\title{
Fertility Histories and Health in Later Life in Italy
}

\author{
Cecilia Tomassini, Giorgio Di Gessa and Viviana Egidi
}

\section{Background}

As stated in the first chapter of this volume, numerous studies in the past have considered the associations between fertility history (in terms of fertility quantum and tempo) and mortality and different health indicators (Green et al. 1988; Westendorp and Kirkwood 1998; Doblhammer 2000; Alonso 2002; Grundy and Tomassini 2005, 2010; Hank 2010; Grundy and Read 2015) for women and, less frequently, for men (Grundy and Tomassini 2006; Grundy and Kravdal 2008). The literature on this topic suggests that there are several potential mechanisms that may cause associations between fertility histories and health in later life, including selection into parenthood, direct biological factors, as well as indirect effects such as the relative costs and benefits of childrearing. Pregnancy and childbirth may have physiological consequences on long term morbidity: breast cancer, for example, has been found to be positively associated with being childless and with later motherhood and negatively associated with early pregnancy (Amir et al. 2010). Motherhood after age 35 was found to be both positively and negatively associated with health. For instance, late motherhood was found to be positively associated with poor health indicators after age 50 (e.g. including diabetes, hypertension, vision difficulties, impaired physical mobility, higher mortality) (Alonso 2002), but in other studies it was negatively associated with presence of limiting long standing

\footnotetext{
C. Tomassini $(\bowtie)$

Department of Economics, University of Molise, Campobasso, Italy

e-mail: cecilia.tomassini@unimol.it

G. Di Gessa

Department of Global Health \& Social Medicine, King's College London, London, UK

e-mail: giorgio.di_gessa@kcl.ac.uk

V. Egidi

Department of Statistics, Sapienza University of Rome, Rome, Italy

e-mail:Viviana.Egidi@uniroma1.it

(C) The Author(s) 2018

G. Doblhammer and J. Gumà (eds.), A Demographic Perspective on Gender,

Family and Health in Europe, https://doi.org/10.1007/978-3-319-72356-3_11
} 
illnesses (Doblhammer 2000; Grundy and Tomassini 2005). These differences seem to vary by cohort, and this can explain the inconsistence of the results found in the literature. For example, later motherhood today is linked to fertility techniques that may have negative consequences on health (e.g. breast cancer) although the literature mainly rejects this association (Salhab et al. 2005).

Selection may play an important role when considering health and mortality after the reproductive period: women aged 50 and older are selected for premature mortality (for example linked to childbearing itself as maternal mortality), even if this is becoming increasingly rarer for modern populations. Childlessness in the past may have been related to poor health: women with health problems tended not to get married and not to have children. At the same time being able to conceive a child at earlier or later ages may be an indicator of overall good health status and slower ageing (Doblhammer and Oeppen 2003). This is true also for younger cohorts, even if the proportion of people who rationally choose to remain childless is higher than in the past.

It has been also argued that health may also be affected by other psychological factors such as stresses and role changes. On the socio-economic side, personal and family income may be reduced by the costs of childbearing. Early pregnancies may hamper education and work careers and therefore have an impact on future socio-economic status and, directly and indirectly, on health (Fletcher and Wolfe 2009).

In order to disentangle all these different mechanism and pathways, some studies have considered men and women separately, as women are expected to experience the physiological consequences of pregnancy and childbirth while both sexes should be affected by the psychological and economic components of the association.

Additionally, considering different types of health outcomes may provide an interesting insight on the mechanisms that link selected indicators of fertility quantum and tempo and health, helping to identify the process underlined in this association. Furthermore, to our knowledge, no studies have examined this association in the context of a familialistic country such as Italy. Most studies have been based on countries in Northern and Central Europe, where intergenerational exchanges are less frequent and children leave the parental home early, and where the hypothesised psychological factors may be less strong. The notion of the familialistic culture has been used in the past to explain the strong family ties existing in southern Europe (Reher 1998) where, for example, intergenerational co-residence tends to continue until children leave the parental home to get married; and even then they normally live close to their parents (Tomassini et al. 2003). In a familialistic country with strong family ties, frequent contact between generations may play a significant role in enhancing the role of parenthood against childlessness, especially for the subjective indicators of health. Additionally it should be stressed that familialistic countries are characterised by the unbalanced division of house and care work (Anxo et al. 2011): women's multiple roles may affect (positively for the "role enhancing theory" or negatively for the "role strain model") the perception of their health status. 
From a demographic point of view, Italy is characterised by sharp declining fertility: the TFR for cohorts born around 1930 was around 2.3, while it declined to 1.6 for those born around 1960. The proportion of childless women is less than $20 \%$ for all cohorts considered in this study. Southern Italy is characterised by a higher and earlier level of fertility: on average, for cohorts born in the 30s, Southern women had one more child compared to their Central and Northern counterparts. Additionally more than half of Southern women had three or more children compared to a quarter in Central and Northern Italy (Santini 1995). Italy is also characterised by a high level of late fertility: $40 \%$ of births occurred after age 30 in Northern and Central Italy for the 1930 cohort and 37\% for the 1960 cohort (in the South 45 and $30 \%$ respectively). These trends continue, even in presence of a further decline in the total fertility rate: in 2013, around $8 \%$ of births occur after age 39 (ISTAT 2015) compared to less than 4\% in England and Wales (ONS 2015). Such trends may indicate how Italian later mothers are less selected in terms of "slower ageing" compared to other countries.

In this chapter, we focus on women and men aged 50 and over with complete fertility histories using two nationally representative surveys. Using different data sources allows us not only to consider different outcomes in health, but also to provide a rich picture of the associations between health and fertility indicators. Our main aim is to examine the association of fertility quantum (for all respondents) and fertility quantum and tempo (for parents only) with several indicators of the health status. These relations are analysed by taking different socio-economic indicators into consideration in order to control for these confounding factors.

\section{Methods}

To explore the associations between fertility histories indicators and health we use data from two sources of data. It is not common to collect information both on fertility histories and current (or past) health status in Italy. The only exceptions are the two datasets we use in this chapter.

The first dataset is the Italian Survey on Family and Social Relations (ISF), carried out by the Italian Institute of Statistics in 2009. This cross-sectional survey has a very high response rate (above $80 \%$ ) and investigates several aspects of family and social networks. From the original sample of around 60,000 individuals we selected respondents aged 50 and over $(\mathrm{N}=17,973)$ with completed fertility histories. The large sample size and the high response rate are the strong points of this source of data, even if the health variables collected are few and no references to early life socio-economic conditions are included in the questionnaire.

The second are data from the Survey of Health, Ageing and Retirement in Europe (SHARE), a multidisciplinary ongoing longitudinal survey of individuals aged 50 and over living in Austria, Belgium, Switzerland, Germany, Denmark, Spain, France, Italy, Greece, the Netherlands, and Sweden. Specific details of 
sampling frames and methodology, weighting strategies, and questionnaires have been reported elsewhere (Börsch-Supan et al. 2008; Börsch-Supan and Jürges 2005; Schröder 2011). The first wave of SHARE took place in 2004/05 with later waves conducted biennially. Waves 1, 2, 4 and 5 collected data on the respondents' current living conditions and health. Information about the respondents' life histories were collected only in wave 3 (SHARELIFE, 2008/09), when no additional households were sampled; histories were therefore only collected from respondents who participated in either wave 1 or 2 . Given our interest in the histories and the baseline characteristics, the data from waves 4 and 5 were not relevant. In order to assess the relationship between fertility history indicators and health, we used the pooled baseline interviews of Italian respondents aged 50 and older from waves 1 and 2 $(\mathrm{N}=3709)$ for whom information on their fertility history had been collected ( $\mathrm{N}=2383$, i.e. $64 \%$ of the pooled sample of initial interviews). SHARE was used as it collects all the information needed for these kinds of studies (fertility histories and present and past health indicators), but the low response rate and the small sample size may not produce stable results.

\section{Outcome Variables}

Our key health outcomes were self-rated health (SRH), depressive symptoms, and various measures of functional limitations. In the ISF survey, SRH was measured by the WHO question (De Bruin et al. 1996) adopting a 5-point ordinal scale (very good, good, fair, poor, and very poor), whereas in SHARE self-rated health was measured - in both waves - using the first question of the SF-36 scale (Ware 2000) in which the response options are slightly different (excellent, very good, good, fair, or poor). In our study, the five SRH items were dichotomised into 'poor' (the last two categories of the ISTAT survey and the last of SHARE) versus better health. The 'fair' category of the WHO scale was aggregated with positive evaluations because of its Italian translation, which has more of a positive connotation (Egidi and Spizzichino 2006). Even if the two scales are not directly comparable, we wanted to confirm the directions of the effects of the socio-demographic and fertility characteristics on self-perception of health.

Functional limitations were measured through a series of indicators targeting situations in which health disorders and conditions had impacted people's usual activities. First, both ISF and SHARE respondents were asked whether they had experienced "limitation in activities people usually do because of health problems for at least the past six months". This single-question item is a validated measure, which approximately captures global activity limitations (Jagger et al. 2010). We categorised respondents as limited regardless of severity of the limitation. SHARE respondents were also asked to fill in two functional limitations scale focusing on different aspects of functional independence: the Activity of Daily Living (ADL) (Katz et al. 1963) and the Instrumental Activity of Daily Living (IADL) 
scales (Lawton and Brody 1969). In the first case, respondents were asked whether they experienced any difficulties with specific everyday activities that are essential for self-care due to a physical, mental, emotional, or memory problem. Respondents who reported at least one difficulty with basic activities of daily living (activities considered by SHARE are: bathing or showering, dressing, eating, getting in or out of bed, walking across a room, using the toilet) were considered to have an ADL limitation. In the second case, the scale is mainly oriented to social limitations gathering information on more complex activities more related to social life (activities considered by SHARE are: using a map, preparing meals, shopping for groceries, using the telephone, managing medications, maintaining the home, managing finances). Respondents who reported difficulties in at least one of these activities were considered to have an IADL limitation.

SHARE also adopted the EURO-D 12-item scale, a depression symptoms scale especially designed for the mental health evaluation of older European people, the validity and reliability of which has been demonstrated against a variety of relevant clinical assessments (Castro-Costa et al. 2008; Prince et al. 1999). Respondents were asked whether they had experienced any depressive symptoms, such as feeling guilty or being irritable, recently or in the month prior to interview. Those who reported four or more depressive symptoms on the EURO-D scales were classified as reporting depressive symptoms (Prince et al. 1999).

\section{Measures of Interest}

A series of categorical indicators capturing the participants' recall of fertility experiences throughout life were used. In both surveys, participants were asked whether they ever had a biological child, including those who lived for a short time. Those who did were then asked how many children they ever had, including any who died since birth. We distinguished between those who had no biological children, one child, two (as reference category), three, and four or more. For respondents who had at least one biological child regardless of whether the child was still alive or not (i.e. "mothers" and "fathers"), we constructed two dichotomous indicators to capture the timing of births. Taking into account both the year in which each biological child was born and the current year of birth of the parent, we created dummy variables indicating whether the respondent became a parent before the age of 20 and 24 (for mothers and fathers respectively) or after the age of 39.

\section{Other Covariates}

On the basis of the existing literature, we identified characteristics known to be associated with health and accordingly controlled for the following characteristics: age, level of education, marital status, geographical area, wealth, income, and 
labour market participation. Age was recoded into three categories (50-64; 65-75, and 75 and older). Educational qualifications were grouped into three categories: low, mid, and high education, where low level of education is defined as pre-primary or primary level of education, and high refers to upper secondary level of education or above. For marital status, we distinguished between people who were "married or cohabiting", "divorced, separated, or never married", or "widowed". We decided to group the never married with those who are separated or divorced because the number of them with children is very low and it is possible that they used to live with a cohabiting partner. Preliminary analyses were also carried out considering marital history indicators such as the total number of marriages, binary indicators of previous widowhood and divorce, as well as the age at or the length of the latest marital disruption. All these indicators were not significant; therefore, we present results on the marital status at the time of the interview only. Three geographical areas were considered (North, Centre, and South) based on the statistical partition proposed by the Italian National Institute of Statistics (www.istat.it). Wealth was measured using a dichotomised indicator of whether the respondent owned his or her house or not (regardless of whether they were mortgage-free). Similarly, economic resources were measured using a dichotomised indicator of whether the respondent perceived that their household was able to make ends meet with great difficulty or not. Employment history was measured by distinguishing between respondents who have/had ever done any paid work and those who never worked. As an additional control variable for the Italian familialistic context, we introduced in the model a variable measuring whether parents had weekly contact with their children. Our hypothesis was to test if family closeness buffers the association found between indicators of fertility histories and subjective health.

No measures of previous health conditions were asked in the ISF, whereas SHARE collected several indicators of participants' recall of health in childhood (defined as by when respondents were born up to and including when they were 15 years old). In particular, we considered an indicator of early life poor health if respondents missed school for more than one month, whether they recall being confined to bed or home for more than one month, or whether they were in hospital for a month or more because of a health condition during childhood. Moreover, SHARE asks questions about the respondents' socio-economic conditions during childhood, and we considered two proxies of these conditions using information on whether the respondents were living with both natural parents at the age of 10 , and whether they had enough books to fill one shelf or one or more bookcases in the household.

\section{Statistical Analysis}

Our analyses of cross-sectional relationships between fertility history and health consisted of two steps. First, we assessed the impact of the number of biological children ever born on health among all baseline respondents, controlling for 
demographic and socio-economic factors. Second, restricting the analyses to mothers and fathers, we also controlled for the timing of births. Among SHARE respondents only, we also accounted for health at childhood in subsequent models. Given the binary nature of the outcome variables, we used binomial logistic regression analyses. All analyses on the ISF data were performed using SPSS, weighted by our standardisation of the coefficient provided by ISTAT. All analyses on the SHARE data were performed using Stata (Stata Corp 2013), and adjusted for the survey design effects. No weights were available for the pooled sample used in this study; however, all characteristics relevant for weighting were controlled for in the multivariate analyses.

\section{Results}

\section{Descriptive Statistics}

Table 1 shows the distribution of demographic, socio-economic, fertility, and health characteristics at baseline of both ISF and Italian SHARE respondents. Overall, about $40 \%$ of respondents in both surveys had two children, with slightly higher percentages of adults with three or more children among Italian SHARE respondents. Among parents, one in six fathers and one in 16 mothers had at least one child when they were 40 or older. In both surveys, about seven percent of the respondents became fathers and mothers before the age of 24 and 20 respectively. Male respondents in both surveys were more likely to report better health compared to women for all the variables considered. As for the indicators of socio-economic and health conditions at childhood among SHARE respondents, no gender differences were found, with about $10 \%$ of respondents who recalled missing school or spending one month or more confined in bed or in the hospital for one month or more because of a health condition. Table 1 also shows that SHARE respondents were more likely to be younger, married, and from the Centre or South of Italy compared to ISF respondents.

\section{Associations Between Number of Children and Health Indicators-All Respondents}

Figure 1 shows results from logistic regression models, which investigated associations between number of children and SRH, limitations, and depressive symptoms, controlling for socio-economic and demographic characteristics. Full details of the associations are shown in Table 2. For reasons of space, results for SRH and global activity limitations are presented only for IFS respondents. 
Table 1 Percentage distribution of demographic, socio-economic, fertility and health variables included in SHARE and ISF

\begin{tabular}{|c|c|c|c|c|}
\hline \multirow[t]{2}{*}{ All respondents } & \multicolumn{2}{|c|}{ ISF respondents } & \multicolumn{2}{|c|}{ SHARE respondents } \\
\hline & $\begin{array}{l}\text { Men } \\
(\mathrm{N}=8232)\end{array}$ & \begin{tabular}{|l} 
Women \\
$(\mathrm{N}=9741)$
\end{tabular} & $\begin{array}{l}\text { Men } \\
(\mathrm{N}=1091)\end{array}$ & $\begin{array}{l}\text { Women } \\
(\mathrm{N}=1292)\end{array}$ \\
\hline $50-64$ & 52.8 & 46.5 & 51.7 & 59.9 \\
\hline $65-74$ & 26.5 & 26.1 & 34.9 & 27.3 \\
\hline $75+$ & 20.7 & 27.4 & 13.4 & 12.8 \\
\hline Married or cohabiting & 78.8 & 57.4 & 89.4 & 77.1 \\
\hline $\begin{array}{l}\text { Divorced/separated/never } \\
\text { married }\end{array}$ & 14.8 & 13.9 & 7.0 & 6.1 \\
\hline Widowed & 6.4 & 28.7 & 3.6 & 16.8 \\
\hline Low education & 37.3 & 53.2 & 47.3 & 59.7 \\
\hline Medium education & 27.8 & 21.1 & 23.0 & 17.2 \\
\hline High education & 34.9 & 25.7 & 29.7 & 23.1 \\
\hline Home owner & 80.2 & 77.8 & 82.3 & 80.1 \\
\hline $\begin{array}{l}\text { Household meets end with great } \\
\text { difficulty }\end{array}$ & 66.6 & 38.7 & 19.9 & 21.7 \\
\hline In paid work (currently or ever) & 92.2 & 52.1 & 95.3 & 67.1 \\
\hline North & 47.4 & 47.2 & 37.6 & 39.0 \\
\hline Centre & 20.4 & 20.6 & 26.0 & 24.7 \\
\hline South & 32.2 & 32.2 & 36.4 & 36.3 \\
\hline Self-rated Health $=$ Poor & 12.4 & 17.1 & 7.9 & 11.1 \\
\hline With any LLI & 31.6 & 39.1 & 32.1 & 44.3 \\
\hline With 1+ ADL limitations & & & 6.1 & 9.6 \\
\hline With 1+ IADL limitations & & & 8.2 & 16.3 \\
\hline With depressive symptoms & & & 20.5 & 41.3 \\
\hline No children & 13.6 & 12.8 & 10.5 & 10.1 \\
\hline 1 child & 19.9 & 21.5 & 18.0 & 17.1 \\
\hline 2 children & 39.6 & 39.2 & 40.9 & 39.2 \\
\hline 3 children & 15.5 & 17.3 & 19.7 & 20.5 \\
\hline 4+ children & 6.6 & 9.2 & 10.9 & 13.3 \\
\hline $\begin{array}{l}\text { Never missed school, in bed, or } \\
\text { in hospital for } 1+\text { month in } \\
\text { childhood }\end{array}$ & & & 91.6 & 89.7 \\
\hline $\begin{array}{l}\text { Living with both natural parents } \\
\text { at } 10\end{array}$ & & & 89.8 & 90.2 \\
\hline Books filled $1+$ shelf in $\mathrm{HH}$ & & & 23.2 & 25.7 \\
\hline Parents only & $(N=7122)$ & $(\mathrm{N}=\mathbf{8 4 8 5})$ & $(N=976)$ & $(\mathrm{N}=1160)$ \\
\hline Age first $<20$ (24 for men $)$ & 8.9 & 7.6 & 7.3 & 6.6 \\
\hline Late parenthood & 16.1 & 6.0 & 17.3 & 6.2 \\
\hline
\end{tabular}

Sources SHARE 2004/05, 2006/07 and SHARELIFE 2008/09; ISF 2009. Weighted results 

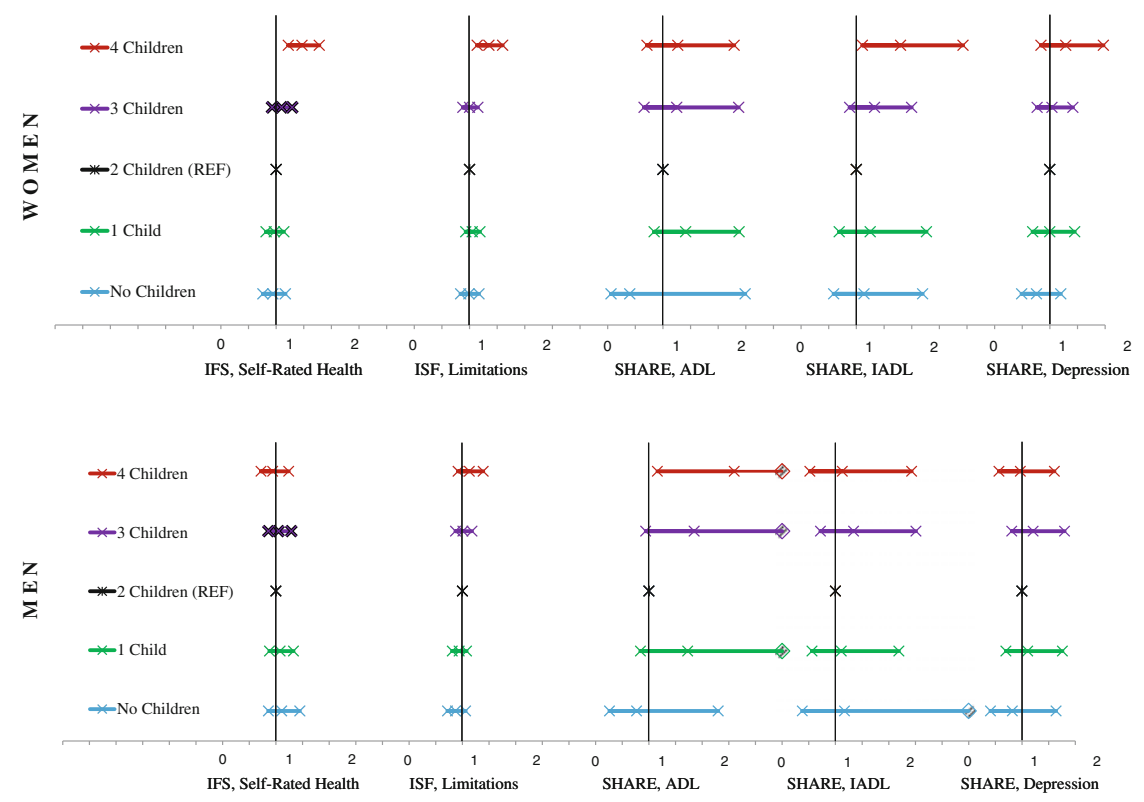

Fig. 1 Odds ratios and 95\% confidence intervals, from the logistic model for health indicators for all respondents aged 50 and over. Controlling for age, marital status, education, region, housing tenure, and household income satisfaction

Regardless of the health outcome considered, Fig. 1 shows no significant differences between both male and female respondents who are childless or only had one child and those who had two children (the reference category). Similarly, no significant associations were found between having had three children and health, the only exception being male respondents who were marginally more likely to report ADL limitations $(p<0.10)$. However, having had four or more children is associated with an increased likelihood of reporting poor health, particularly among female respondents. In particular, women who gave birth to four or more children were significantly more likely to report poor SRH, global activity limitations, and IADL limitations compared to those who had two children. Men with four or more children were significantly more likely to report ADL limitations. No significant associations between the number of children and depressive symptomatology were found. Associations with other baseline covariates were broad, as would be expected from previous studies. Older respondents were significantly more likely to report poor health, global limitations, and depressive symptoms; those with higher educational levels were significantly less likely to report poor SRH, global limitations, ADL and IADL limitations, and depressive symptoms compared to those with the lowest education level. There was also a reverse association among the perception of economic resources available, employment history (particularly among men), and health disadvantage. Similarly, results suggest that respondents who were not currently married were more likely to report poor SRH and limitations; similarly, 


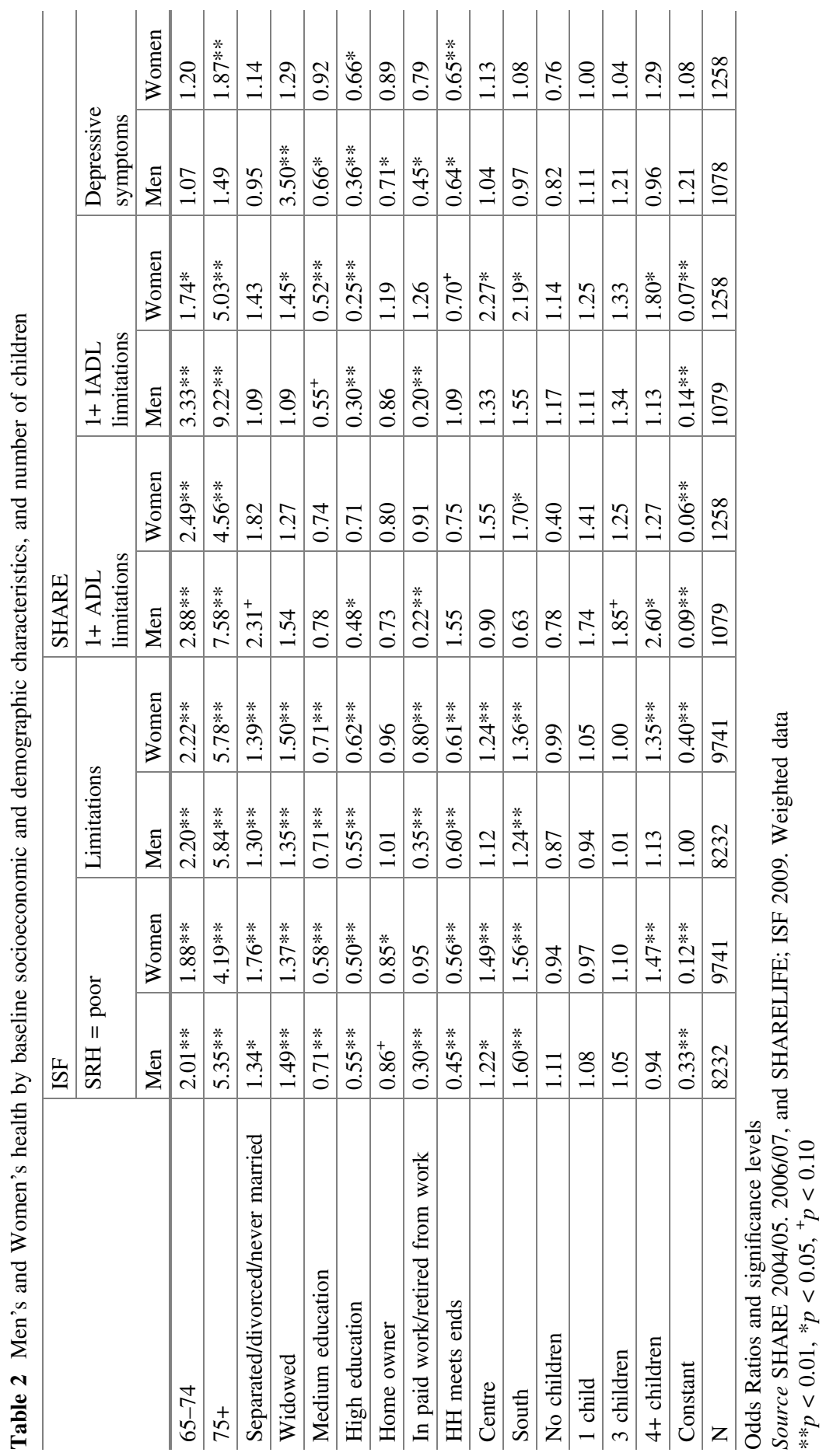


widowed men and women were respectively more likely to report depressive symptoms and IADL limitations. Finally, respondents from the South of Italy were more likely to report poor SRH, global limitations, and-among women-ADL and IADL limitations compared to those who live in the North of Italy.

\section{Associations Between Quantum and Tempo Fertility Indicators and Health Indicators Among Parents}

Figure 2 shows results from logistic regression models which, restricting analyses to parents only, investigated associations between fertility quantum and tempo and SRH, limitations, and depressive symptoms, controlling for socio-economic and demographic characteristics. As before, results for SRH and global activity limitations are presented only for IFS respondents. Full details of the associations are shown in Table 3.

When restricting analyses to respondents who have had at least one child, Fig. 2 shows that for all five outcomes having had one or three children was not associated with health. However, again there was some evidence to suggest that women who had four or more children were significantly more likely to report poor SRH, global
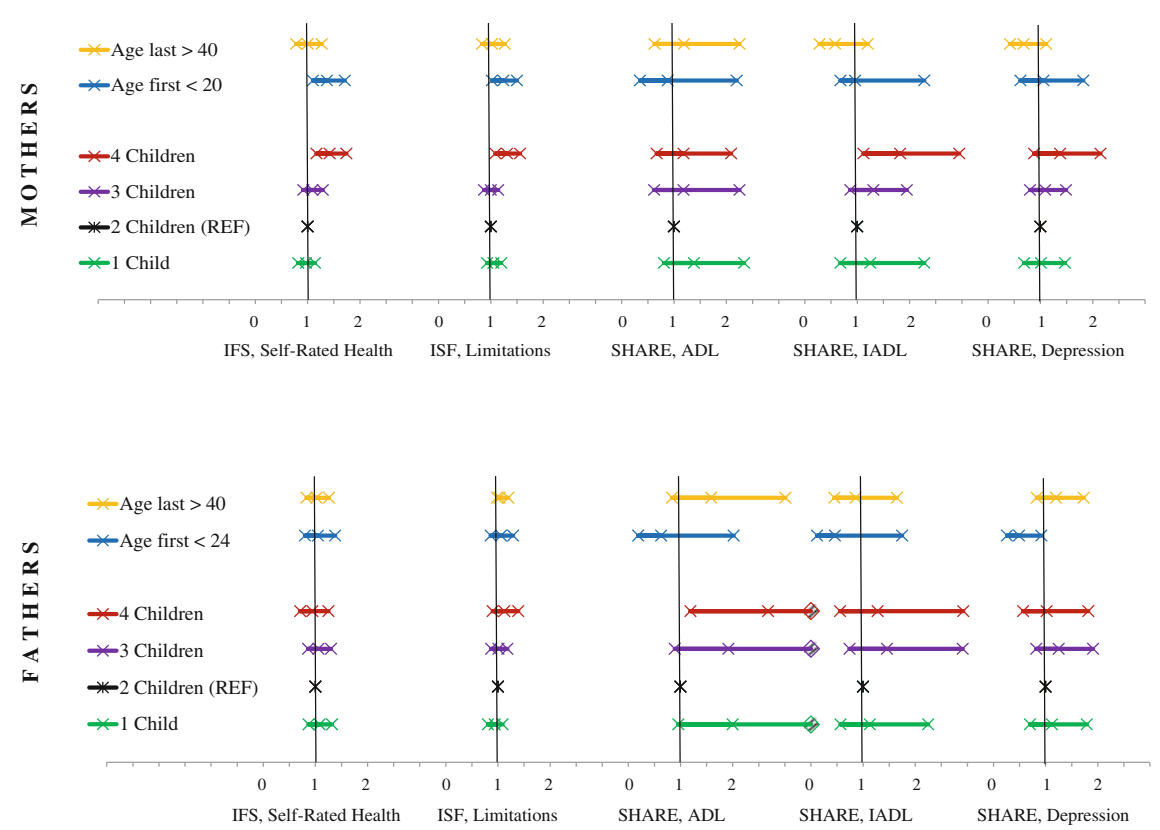

Fig. 2 Odds ratios and 95\% confidence intervals, from the logistic model for health indicators for all parents aged 50 and over. Controlling for age, marital status, education, region, housing tenure, and household income satisfaction 


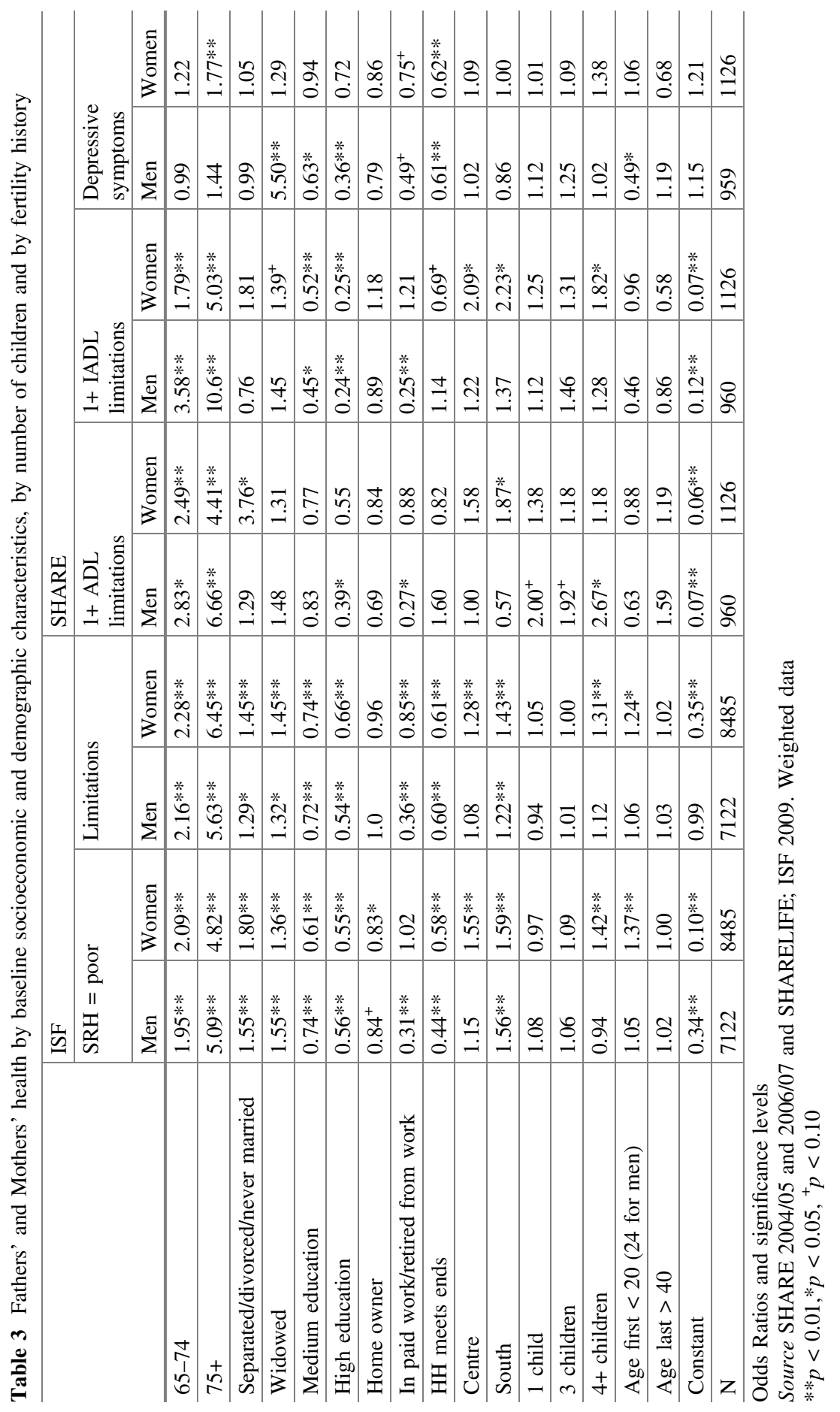


activity limitations, and IADL limitations compared to those who had two children, whereas men were more likely to report ADL limitations. No significant associations between four or more children and depressive symptoms were found.

As for the indicators which capture the timing of births, results suggest that becoming a parent at the age of 40 or older was not associated with any of the health indicators, for neither fathers nor mothers. On the other hand, mothers who gave birth before the age of 20 were significantly more likely to report poor SRH and global activity limitations compared to women who became mothers at older ages. No associations were found between early parenthood and functional limitations. However, male respondents who became fathers at 23 or younger were less likely to report depressive symptoms compared to those who had their first child later at older ages.

\section{Conclusions and Discussion}

There are several striking results from our analysis. Unlike other studies, our findings do not show childlessness to be associated with any problems in the health indicators used in this chapter. There are no disadvantages for those without children and therefore, in the context of a familialistic country, without potential social support from children. Selection may have played a role here, if we hypothesised that only the fittest childless people survived to older age. However, given that for the cohorts born after the 30 s the progression rate to parity one was quite high (Santini 1995), and that mortality levels in Italy for these generations were not higher compared to other Western countries (Human Mortality Database 2015), selection itself cannot entirely explain such findings.

As previous studies have shown, having four or more children has an important impact on poor self-rated health, presence of limiting illnesses, and IADL limitations among older women, and on ADL limitations among older men. These results do not shed a clear light on the pathways (physiological vs psychological) that may link fertility histories and health; however, they do suggest that high parity may have negative consequences on health, especially for women. As shown in other studies (Grundy and Tomassini 2005; Christensen et al. 1998), not only do women with high parity more frequently rate their health as poor or declared mild or severe limiting illnesses, but they also seem to suffer problems with IADL. Because IADLs, unlike ADLs, include the social dimensions of functional limitations (such as shopping for groceries, managing finances, or maintaining the home) rather than the mere functional ones, this female disadvantage suggests that high parity women may have spent their lives with fewer external activities in addition to their family responsibilities. This may be linked to the presence of many children itself as well as to a more traditional and deprived environment, and it is possible that this relative disadvantage continues in later life. It is also possible that the unbalanced gender division in traditional Italian families in performing family work may play a significant role in female disadvantage related to high parity (Anxo et al. 2011). 
When parents are considered, early motherhood has the same significant negative effect on self-rated health and presence of functional limitations as shown in previous studies, while it is protective for men regarding depression. One possible explanation for the latter result may be because younger fathers become grandfathers earlier in life and this role has beneficial consequences on men's mental health (Di Gessa et al. 2015). This result may suggest that the association of fertility behaviour and psychological health is not as strong for women compared to the other health indicators used in this chapter, as found in other previous studies (Hank and Wagner 2013).

In order to expand our results, we also tested whether marital histories may have affected the associations found with the fertility indicators. Introducing in the model variables such as the total number of marriages, binary indicators of previous widowhood and divorce, as well as the age at or the length of the latest marital disruption change the relationship nor the strength of the associations. All such variables were never significant, suggesting that, in this context, the actual marital status is more important than marital histories for health and health related indicators. Furthermore, only among SHARE respondents, we repeated the same analyses also controlling for health and socio-economic conditions at childhood in subsequent models. The results (reported in Tables 4 and 5) showed that only the indicator of early life poor health was significantly associated with current health for all the outcomes considered except IADL limitations; such associations were significant only among women and mothers. However, even accounting for early life conditions, the direction and strength of associations between participants' fertility experiences throughout life and the outcomes of interest did not change.

We also considered, as a fertility history indicator, the occurrence of close births, defined as giving birth to two children, including twins, in less than two consecutive calendar years, but the variable was never significant for the health dimensions we considered in both samples. Some previous studies have found a negative association between closely spaced birth (including twins) and health (Grundy and Tomassini 2005), suggesting potential physiological harm or an additional load of stress for parents, but this effect was not found for any of the health indicators used in this study, suggesting no parental strain due to rearing more than one young child at once.

Another effort to clarify the relations between fertility quantum and tempo and health was introducing the model interactions between age groups and geographic area and number of children. We hypothesised that, for example, the effect of early motherhood and high parity on health could be positive among older cohorts of women from the South, given that among such groups higher and earlier fertility were more accepted and common compared to the rest of the country. We found a significant positive effect of the interaction between early pregnancies and living in the South only among mothers, while the main effect of both variables remained significant. This result may suggest that the consequences of early pregnancy on later life health might be less strong in Southern Italy, confirming our hypothesis.

Another peculiar characteristic of Italy is the potential influence of the quantity and quality of family exchanges on different aspects of health. Our results (not shown) indicate that even controlling for the quantity of contacts between mothers 


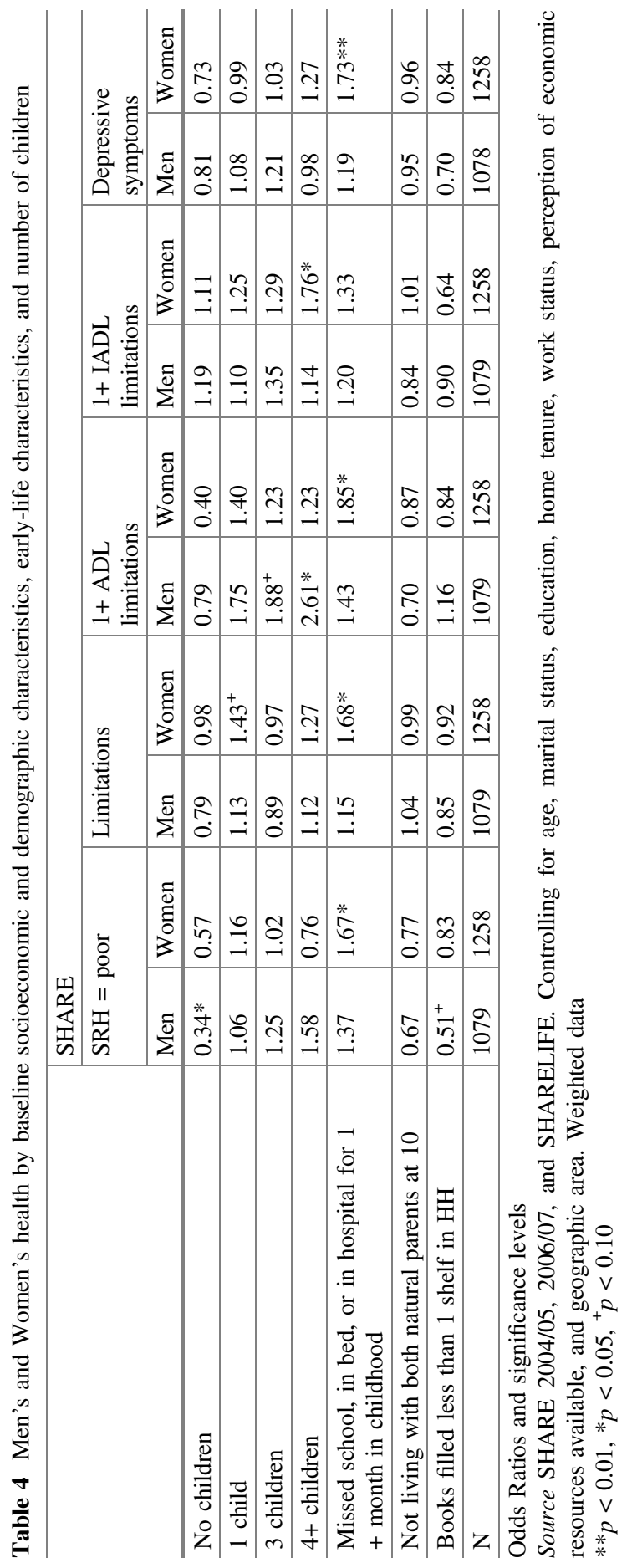




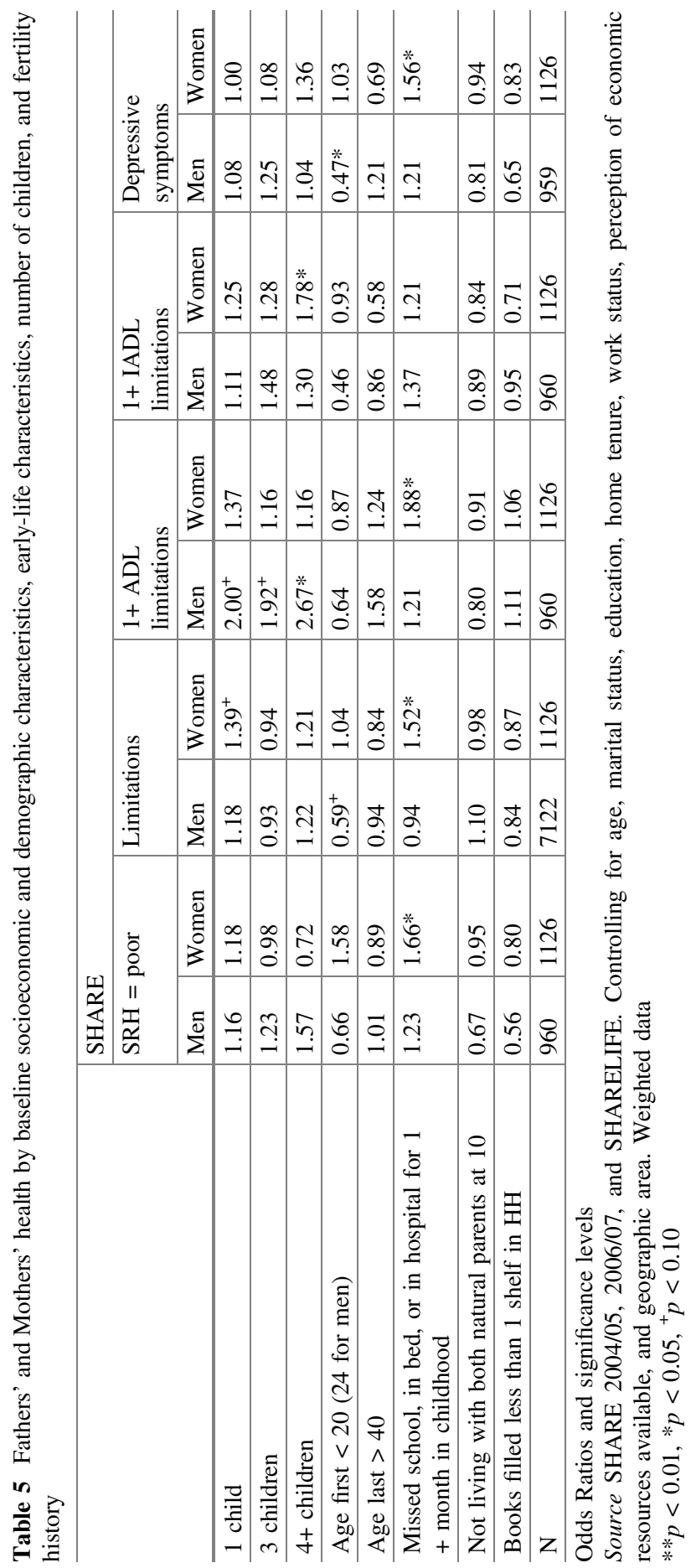


and children, such close relations do not affect the association between high parity and health, suggesting that the potential physiological consequences of multiple pregnancies on women's health may not be buffered by close relations with children.

Although our study provides additional light on the relationship between parenthood and health at later life, it also has limitations. First, our analysis is based on cross-sectional data, and it is therefore possible that health problems may have prevented men and women from having any or additional children. Interestingly, however, we have not found any negative effect of being childless or with parity 1 on any indicators of health as in previous studies, suggesting that if reverse pathways (i.e. poor health preventing having any or additional children) shaped such associations, these were not significant.

Second, selection may act differently for different socio-economic groups and for different cohorts. For the older cohort, high parity was associated with lower socio-economic status and with the South of Italy (Santini 1995), but we are not able to control for those variables at the time of birth of the child. Still these results hold when considering current socio-economic indicators. Furthermore, selection by death may bias our sample and could explain why in our study we did not find any disadvantage associated with childlessness among women; however, as mortality before age 50 is very low in Italy (Human Mortality Database 2015), this source of distortion should be minimal.

Third, this study used data from two different sources, IFS and SHARE. Even though the distributions of the variables of interest seem to be relatively comparable across both datasets, the demographic and socio-economic distributions of SHARE respondents differ considerably, with SHARE respondents being younger, more likely to be married, with low education, and from the Centre-South of Italy compared with IFS participants. This may be due to a combination of initial low response rate of the SHARE survey, longitudinal attrition, and the fact that no weights were available for the pooled sample used in this study (Di Gessa 2011). Our research is based on complete case analyses of SHARE, and does not consider how sample attrition might potentially bias associations (Fitzgerald et al. 1998).

This study has tried to provide additional insights in the relation between fertility histories indicators and health in the context of a familialistic country such as Italy. In addition to the physiological justification that may explain the differences found between men and women for the detrimental effect on ADL of high parities, a more complicated link may be hypothesised. The negative effect of high parity on IADL for women may indicate a socially deprived environment for women with more children which the variables included in the questionnaires are not able to capture. Furthermore, in a familialistic country women are exposed to a greater overload of unpaid work (house chores and care activities), both during adult and later life. Both factors may explain the female disadvantage in terms of high parity and early motherhood. Because these characteristics are becoming rarer among younger cohorts (in 2013 only $0.4 \%$ of the births occurred to teenagers mothers compared to $4.7 \%$ in England and Wales), we hypothesised that these factors will not play a major role in younger cohorts. 


\section{References}

Alonso, A. (2002). Long term health consequences of delayed childbirth: NHANES III. Women's Health Issues, 12, 37-45.

Amir, E., Freedman, O. C., Seruga, B., \& Evans, G. D. (2010). Assessing women at high risk of breast cancer: A review of risk assessment models. Journal of the National Cancer Institute, 102(10), 680-691.

Anxo, D., Mencarini, L., Pailhé, A., Solaz, A., Tanturri, M. L., \& Flood, L. (2011). Gender differences in time use over the life course in France, Italy, Sweden, and the US. Feminist Economics, 17(3), 159-195.

Börsch-Supan, A., \& Jürges, H. (2005). The survey of health, aging, and retirement in Europemethodology. Mannheim: Research Institute for the Economics of Aging.

Börsch-Supan, A., Brugiavini, A., Jürges, H., Kapteyn, A., Mackenbach, J., Siegrist, J., \& Weber, G. (2008). First results from the survey of health, ageing and retirement in Europe (20042007). In Starting the longitudinal dimension. Mannheim: Mannheim Research Institute for the Economics of Aging (MEA).

Castro-Costa, E., Dewey, M., Stewart, R., Banerjee, S., Huppert, F., Mendonca-Lima, C., et al. (2008). Ascertaining late-life depressive symptoms in Europe: An evaluation of the survey version of the EURO-D scale in 10 nations. The SHARE project. International Journal of Methods in Psychiatric Research, 17(1), 12-29. https://doi.org/10.1002/mpr.236.

Christensen, K., Gaist, D., Jeune, B., \& Vaupel, J. (1998). A tooth per child? Lancet, 352, 204.

De Bruin, A., Picavet, H. S. J., \& Nossikov, A. (1996). Health interview surveys. Towards international harmonization of methods and instruments (p. 58). European Series: WHO Regional Publications.

Di Gessa, G. (2011). 'Active ageing' and health: An exploration of longitudinal data for four European countries. Ph.D. thesis. (Ph.D.), London School of Hygiene \& Tropical Medicine, London.

Di Gessa, G., Glaser, K. F., \& Tinker, A. M. (2015). The health impact of intensive and nonintensive grandchild care in Europe: New evidence from SHARE. Journals of Gerontology Series. B, Psychological Sciences and Social Sciences. https://doi.org/10.1093/geronb/gbv055.

Doblhammer, G. (2000). Reproductive history and mortality later in life: A comparative study of England and Wales and Austria. Population Studies, 54, 169-176.

Doblhammer, G., \& Oeppen, J. (2003). The effect of frailty and mortality selection on the Peerage. Proceedings the Royal Society Series B Biological Sciences, 270, 1541-1547.

Egidi V, \& Spizzichino D. (2006). Perceived health and mortality: A multidimensional analysis of ECHP Italian data. Genus, LXII(3-4).

Fitzgerald, J., Gottschalk, P., \& Moffit, R. (1998). An analysis of sample attrition in panel data: The Michigan panel study of income dynamics. The Journal of Human Resources, 33(2) (Special Issue: Attrition in Longitudinal Surveys), 251-299.

Fletcher, J. M., \& Wolfe, B. L. (2009). Education and labor market consequences of teenage childbearing: Evidence using the timing of pregnancy outcomes and community fixed effects. Journal of Human Resources, 44, 303-325.

Green, A., Beral, V., \& Moser, K. (1988). Mortality in women in relation to their childbearing history. British Medical Journal, 297, 391-395.

Grundy, E., \& Kravdal, Ø. (2008). Reproductive history and mortality in late middle age among Norwegian men and women. American Journal of Epidemiology, 167, 271-279.

Grundy, E., \& Read, S. (2015). Pathways from fertility history to later life health: Results from analyses of the English longitudinal study of ageing. Demographic Research, 32, 107-146.

Grundy, E., \& Tomassini, C. (2005). Fertility history and health in later life: A record linkage study in England and Wales. Social Science and Medicine, 61, 217-228.

Grundy, E., \& Tomassini, C. (2006). Fatherhood history and later life health and mortality in England and Wales: A record linkage study. Social Biology, 53(3-4), 189-205. 
Grundy, E, \& Tomassini, C. (2010). Marital history, health and mortality among older men and women in England and Wales. BMC Public Health, 10.

Hank, K. (2010). Child bearing history, later-life health, and mortality in Germany. Population Studies, 64, 275-291.

Hank, K., \& Wagner, M. (2013). Parenthood, marital status, and well-being in later life: Evidence from SHARE. Social Indicators Research, 114, 639-653.

Human Mortality Database. (2015). http://www.mortality.org/.

ISTAT. (2015). Retrieved July 6, 2015 from http://dati.istat.it/.

Jagger, C., Gillies, C., Cambois, E., Van Oyen, H., Nusselder, W., Robine, J.M., \& EHLEIS Team. (2010). The Global Activity Limitation Index measured function and disability similarly across European countries. Journal of Clinical Epidemiology, 63(8):892-899.

Katz, S., Ford, A. B., Moskowitz, R. W., Jackson, B. A., \& Jaffe, M. W. (1963). Studies of illness in the aged: The index of ADL: A standardized measure of biological and psychosocial function. Journal of the American Medical Association, 185(12), 914-919.

Lawton, M. P., \& Brody, E. M. (1969). Assessment of older people: Self-maintaining and instrumental activities of daily living. The Gerontologist, 9(3), 179-186.

ONS. (2015). Birth summary tables, England and Wales, 2013 Statistical Bulletin retrieved from https://www.ons.gov.uk.

Prince, M., Reischies, F., Beekman, A., Fuhrer, R., Jonker, C., Kivela, S., et al. (1999). Development of the EURO-D scale: A European, Union initiative to compare symptoms of depression in 14 European centres. The British Journal of Psychiatry, 174(4), 330-338. https:// doi.org/10.1192/bjp.174.4.330.

Reher, D. (1998). Family ties in Western Europe: Persistent contrasts. Population and Development Review, 24, 203-234.

Salhab, M., Al Sarakbi, W., \& Mokbel, K. (2005). In vitro fertilization and breast cancer risk: A review. International Journal of Fertility and Women's Medicine, 50(6), 259-266.

Santini, A. (1995) Continuità e discontinuità nel comportamento riproduttivo delle donne nel dopoguerra. In Working paper, 53, Dipartimento di Statistica, Università di Firenze.

Schröder, M. (2011). Retrospective data collection in the survey of health, ageing and retirement in Europe. SHARELIFE methodology. Mannheim: Mannheim Research Institute for the Economics of Aging (MEA).

Tomassini, C., Wolf, D., \& Rosina, A. (2003). Parental housing assistance and parent-child proximity in Italy. Journal of Marriage and the Family, 65, 700-715.

Ware, J. E. J. (2000). SF-36 health survey update. Spine, 25, 3130-3139.

Westendorp, R., \& Kirkwood, T. (1998). Human longevity at the cost of reproductive success. Nature, 396, 743-746.

Open Access This chapter is licensed under the terms of the Creative Commons Attribution 4.0 International License (http://creativecommons.org/licenses/by/4.0/), which permits use, sharing, adaptation, distribution and reproduction in any medium or format, as long as you give appropriate credit to the original author(s) and the source, provide a link to the Creative Commons license and indicate if changes were made.

The images or other third party material in this chapter are included in the chapter's Creative Commons license, unless indicated otherwise in a credit line to the material. If material is not included in the chapter's Creative Commons license and your intended use is not permitted by statutory regulation or exceeds the permitted use, you will need to obtain permission directly from the copyright holder. 